\title{
Clinical Study \\ Effect of the Administration of Alpha-Lipoic Acid on Contrast Sensitivity in Patients with Type 1 and Type 2 Diabetes
}

\author{
Anna Gębka, ${ }^{1}$ Ewelina Serkies-Minuth, ${ }^{1}$ and Dorota Raczyńska ${ }^{1,2}$ \\ ${ }^{1}$ Department of Ophthalmology, Medical University of Gdańsk, Smoluchowskiego 17, 80-214 Gdańsk, Poland \\ ${ }^{2}$ Department of Anesthesiology and Intensive Care Medicine, Medical University of Gdańsk, Smoluchowskiego 17, \\ 80-214 Gdańsk, Poland \\ Correspondence should be addressed to Anna Gębka; ania-gebka@wp.pl
}

Received 16 August 2013; Revised 28 November 2013; Accepted 24 December 2013; Published 10 February 2014

Academic Editor: Katarzyna Zorena

Copyright (c) 2014 Anna Gębka et al. This is an open access article distributed under the Creative Commons Attribution License, which permits unrestricted use, distribution, and reproduction in any medium, provided the original work is properly cited.

\begin{abstract}
The aim of this study was to estimate the effects of oral supplementation of alpha-lipoic acid (ALA) on contrast sensitivity (CS) in patients with type 1 diabetes mellitus (T1DM) and type 2 diabetes mellitus (T2DM). The study included 12 patients with T1DM aged $43 \pm 12$ years, 48 patients with T2DM aged $59 \pm 10$ years, and 20 control subjects aged $33 \pm 8$ years. Patients from each studied group, including the control group, were randomly assigned to receive $300 \mathrm{mg}$ of ALA orally once daily for 3 months. CS was evaluated with the Functional Acuity Contrast Test (FACT, Stereo Optical). In the group of patients with T1DM receiving ALA for 3 months CS remained stable and improved in those with T2DM. Reduction of CS in both T1DM and T2DM patients without alpha-lipoic acid supplementation was observed. In the control group on alpha-lipoic acid supplementation, CS improvement was noticed at one spatial frequency. Changes in the CS were observed, despite stable visual acuity and eye fundus image in all studied subjects. Our study demonstrated that oral administration of alpha-lipoic acid had influence on CS in both T1DM and T2DM patients.
\end{abstract}

\section{Introduction}

Diabetic retinopathy (DR) is a chronic and potentially sightthreatening disease resulting from microvascular damage to the retina. Oxidative stress and inflammation have been implicated in the development and progression of this diabetic ocular complication, and thus therapies intervening at the level of pathogenesis are under investigation $[1,2]$. Chronic hyperglycemia, which initiates the development of DR $[3,4]$, generates reactive oxygen species (ROS) in the retinal tissue, characterized by high oxygen partial pressure of oxygen. ROS, mainly superoxide, inactivate glyceraldehyde3-phosphate dehydrogenase (GADPH), an enzyme crucial in the process of glycolysis $[5,6]$. This metabolic block directs substrate flux into biochemical pathways leading to endothelial cell damage. This process constitutes the unifying mechanism of hyperglycemia induced cellular damage [7].

Role of inflammation in the pathophysiology of DR has been highlighted by many researchers in many manuscripts [8-11]. The authors suggest that blood-retinal barrier damage is due to leukocytes attachment to the vascular epithelium, whereas oxidative stress, resulting in endothelial-cell dysfunction, induces the expression of adhesion molecules on the cell surface, such as vascular cell adhesion molecule-1 (VCAM-1) and intracellular adhesion molecule-1 (ICAM-1). Upregulation of these adhesion molecules appears in early DR [12]. The featured processes lead to vision impairment in patients with diabetes. It can be detected by contrast sensitivity (CS) testing, a tool more sensitive than standard visual acuity measures [13-15]. A few studies demonstrated impaired CS in patients with type 1 diabetes mellitus (T1DM) and 2 diabetes mellitus (T2DM) $[14,16]$.

Current efforts are aimed at therapies focused on normalizing the parameters of oxidative stress and inflammation in DR [17-19]. The beneficial effects of alpha-lipoic acid (ALA) on experimental diabetic retinopathy $[20,21]$ prompted us to explore the potential influence of ALA on appearance and progression of retinopathy in diabetic patients, by evaluating their CS.

ALA is a 6,8-dithio-octanoic acid and was first isolated by Reed and colleagues from bovine liver in 1950 [22]. It is 
TABLE 1: Clinical characteristics of patients with T1DM, T2DM, and healthy control subjects.

\begin{tabular}{|c|c|c|c|c|c|c|c|c|}
\hline & Age (years) & $\begin{array}{c}\text { Duration of } \\
\text { diabetes (years) }\end{array}$ & HbAlc (\%) & $\begin{array}{c}\text { Insulin } \\
\text { therapy (\%) }\end{array}$ & $\begin{array}{c}\text { Oral } \\
\text { hypoglycemic } \\
\text { medications } \\
(\%)\end{array}$ & $\begin{array}{c}\text { Without } \\
\text { diabetic } \\
\text { treatment } \\
(N)\end{array}$ & $\begin{array}{c}\text { Oral ALA } \\
\text { supplementation } \\
(N)\end{array}$ & $\begin{array}{l}\text { Complications } \\
(N)\end{array}$ \\
\hline $\begin{array}{l}\text { T1DM patients } \\
N=12\end{array}$ & $43 \pm 12$ & $19 \pm 12$ & $7.4 \pm 1.1$ & 100 & - & - & 5 & 6 with NPDR \\
\hline $\begin{array}{l}\text { T2DM patients } \\
N=48\end{array}$ & $59 \pm 10$ & $7 \pm 8$ & $7.2 \pm 4.8$ & 19 & 77 & 4 & 28 & $\begin{array}{c}7 \text { NPDR } \\
4 \text { ischemic heart } \\
\text { disease } \\
10 \text { hypertension } \\
4 \text { cataract } \\
2 \text { glaucoma } \\
2 \text { pseudophakia }\end{array}$ \\
\hline $\begin{array}{l}\text { Healthy control } \\
\text { subjects } \\
N=20\end{array}$ & $33 \pm 8$ & - & - & - & - & - & 14 & - \\
\hline
\end{tabular}

T1DM: diabetes mellitus type 1; T2DM: diabetes mellitus type 2; $N$ : the number of patients.

an eight-carbon disulphide and contains two thiol groups. ALA, also known as thioctic acid, in vivo may be oxidized or reduced. Its reduced form, dihydrolipoic acid (DHLA), is also biologically active [23]. ALA has an asymmetric carbon, thus resulting in two isomers: R-enantiomer (R-ALA) and S-enantiomer (S-ALA). Lipoic acid supplements contain RALA or a racemic mixture of R-ALA and S-ALA. R-ALA is endogenously synthesized and covalently bound in proteins to the amino group of lysine, a cofactor for mitochondrial dehydrogenase enzyme complex (pyruvate dehydrogenase and alpha-ketoglutarate dehydrogenase mitochondrial enzyme complexes) [24]. Since pyruvate dehydrogenase catalyzes the oxidative decarboxylation of pyruvate to acetylCoA, ALA plays an essential role in pathways generating energy from glucose in mitochondria [25].

As mentioned before, oxidative stress plays an important role in the etiology of DR and antioxidants may have a great contribution in its prophylaxis and treatment. ALA fulfills criteria for an ideal antioxidant stated by Packer et al. [26]: it is absorbed from the diet, then becomes converted in cells into a usable form, and has a low toxicity and both hydrophilic and hydrophobic properties. Because of amphiphilic character of ALA, its antioxidant action takes place in the cytosol, in the plasma membrane, and in the serum and lipoproteins [24]. As an antioxidant, ALA scavenges ROS and is also able to regenerate endogenous oxidized antioxidants, such as glutathione, vitamin C, E, and coenzyme Q10. DHLA has the capacity to reduce the oxidized forms of these antioxidants and thus activates them [27].

In light of the above insights, we attempted to investigate the potential influence of oral supplementation with ALA on contrast sensitivity in patients with T1DM and T2DM.

\section{Materials and Methods}

2.1. Studied Subjects. Twelve patients with type 1 diabetes mellitus ( 8 male, 4 female; mean age $43 \pm 12$ years; $19 \pm 12$ years since diagnosis; $\mathrm{HbA}_{1 \mathrm{c}} 7.4 \pm 1.1 ; 11$ eyes without $\mathrm{DR}, 11$ eyes with nonproliferative DR), 48 patients with type 2 diabetes mellitus ( 29 male, 19 female; mean age $59 \pm 10$ years; $7 \pm 8$ years since diagnosis; $\mathrm{HbA}_{1 \mathrm{c}} 7.2 \pm 4.8 ; 71$ eyes without $\mathrm{DR}, 12$ eyes with nonproliferative DR), and the control group represented by 20 healthy people ( 5 male, 15 female; mean age $33 \pm 8$ years; 38 eyes) participated in this prospective study. Diabetes was diagnosed according to the Polish Diabetes Association guidelines which correspond with the guidelines of the American Diabetes Association [28, 29]. All studied patients underwent a complete ophthalmologic examination, including ETDRS chart visual acuity evaluation, slit-lamp biomicroscopy, and contrast sensitivity (CS) examination. Exclusion criterion was visual acuity lower than $20 / 25$. All patients with type 1 diabetes mellitus (T1DM) had negative medical history of cardiovascular disease, diabetic neuropathy, and nephropathy, and then no other DR eye complications were observed during ophthalmoscopic examinations. Among the ones with type 2 diabetes mellitus (T2DM), 3 patients had positive medical history of cardiovascular disease and 10 of hypertension. All T2DM patients had negative medical history of renal disease and diabetic neuropathy. Moreover, in the T2DM group, 4 patients had early stages of cataract, 2 patients had glaucoma, and two of them had pseudophakia. $77 \%$ of T2DM patients were receiving oral hypoglycemic medications, 19\% were on insulin therapy, and $4 \%$ were without diabetic treatment. Clinical characteristics of the studied patients with T1DM and T2DM as well as the control subjects are presented in Table 1.

Patients with T1DM and T2DM from each studied group, including the control group, were randomly assigned to receive $300 \mathrm{mg}$ of ALA orally once daily for 3 months. Five of the 12 patients with T1DM (3 patients with nonproliferative DR, 2 patients without DR) received $300 \mathrm{mg}$ of ALA orally once daily for 3 months. Twenty-eight patients with T2DM (2 patients with nonproliferative DR, 26 patients without DR) received $300 \mathrm{mg}$ of ALA orally once daily for 3 months. In addition, fourteen of the twenty studied healthy subjects also received $300 \mathrm{mg}$ of ALA orally once daily for 3 months. 
TABLE 2: Characteristics of contrast sensitivity examinations in T1DM patients with and without ALA supplementation at baseline and after 3 months.

\begin{tabular}{|c|c|c|c|c|c|c|}
\hline \multirow[t]{2}{*}{ Spatial frequencies } & \multicolumn{3}{|c|}{$\begin{array}{c}\text { T1DM patients without } \\
\text { ALA supplementation } \\
\text { CS } \times \text { LC }=48 \text { measurements }\end{array}$} & \multicolumn{3}{|c|}{$\begin{array}{c}\text { T1DM patients with } \\
\text { ALA supplementation } \\
\text { CS } \times \text { LC }=40 \text { measurements }\end{array}$} \\
\hline & Baseline & After 3 months & $P$ value & Baseline & After 3 months & $P$ value \\
\hline \multicolumn{7}{|l|}{$\mathrm{A}-1.5 \mathrm{cpd}$} \\
\hline Mean. \pm SD & $6.5 \pm 1.5$ & $6.0 \pm 1.6$ & & $5.6 \pm 1.1$ & $5.6 \pm 1.2$ & \\
\hline Range & $3.0-9.0$ & $3.0-9.0$ & $P=0.009^{* *}$ & $4.0-8.0$ & $3.0-8.0$ & $P=0.614$ \\
\hline Median & 7.0 & 6.0 & & 5.0 & 5.0 & \\
\hline 95\% CI & {$[6.1 ; 7.0]$} & {$[5.5 ; 6.4]$} & & {$[5.3 ; 6.0]$} & {$[5.2 ; 5.9]$} & \\
\hline \multicolumn{7}{|l|}{ B-3 cpd } \\
\hline Mean. \pm SD & $6.0 \pm 1.4$ & $5.5 \pm 1.6$ & & $5.1 \pm 1.7$ & $5.0 \pm 1.6$ & \\
\hline Range & $2.0-8.0$ & $1.0-9.0$ & $P=0.010^{* *}$ & $2.0-8.0$ & $1.0-9.0$ & $P=0.770$ \\
\hline Median & 6.0 & 6.0 & & 5.0 & 5.0 & \\
\hline $95 \%$ CI & {$[5.6 ; 6.5]$} & {$[5.1 ; 6.0]$} & & {$[4.5 ; 5.6]$} & {$[4.5 ; 5.5]$} & \\
\hline \multicolumn{7}{|l|}{ C-6 cpd } \\
\hline Mean. \pm SD & $5.3 \pm 2.2$ & $4.8 \pm 2.0$ & & $4.2 \pm 2.2$ & $4.2 \pm 2.2$ & \\
\hline Range & $0.0-8.0$ & $0.0-8.0$ & $P=0.005^{* *}$ & $0.0-8.0$ & $0.0-8.0$ & $P=0.947$ \\
\hline Median & 6.0 & 5.0 & & 4.0 & 4.0 & \\
\hline $95 \% \mathrm{CI}$ & {$[4.6 ; 5.9]$} & {$[4.2 ; 5.3]$} & & {$[3.5 ; 4.9]$} & {$[3.5 ; 4.9]$} & \\
\hline \multicolumn{7}{|l|}{$\mathrm{D}-12 \mathrm{cpd}$} \\
\hline Mean. \pm SD & $3.6 \pm 2.6$ & $3.1 \pm 2.4$ & & $2.9 \pm 2.3$ & $2.7 \pm 2.3$ & \\
\hline Range & $0.0-8.0$ & $0.0-8.0$ & $P=0.020^{* *}$ & $0.0-7.0$ & $0.0-7.0$ & $P=0.626$ \\
\hline Median & 4.0 & 4.0 & & 3.0 & 2.0 & \\
\hline $95 \% \mathrm{CI}$ & {$[2.8 ; 4.4]$} & {$[2.4 ; 3.8]$} & & {$[2.1 ; 3.6]$} & {$[2.0 ; 3.5]$} & \\
\hline \multicolumn{7}{|l|}{ E-18 cpd } \\
\hline Mean. \pm SD & $2.1 \pm 2.2$ & $2.0 \pm 2.0$ & & $1.7 \pm 1.9$ & $1.5 \pm 1.9$ & \\
\hline Range & $0.0-7.0$ & $0.0-5.0$ & $P=0.530$ & $0.0-5.0$ & $0.0-6.0$ & $P=0.365$ \\
\hline Median & 1.0 & 1.5 & & 0.5 & 0.0 & \\
\hline $95 \% \mathrm{CI}$ & {$[1.4 ; 2.7]$} & {$[1.4 ; 2.5]$} & & {$[1.1 ; 2.3]$} & {$[0.8 ; 2.1]$} & \\
\hline
\end{tabular}

CS $\times$ LC: the number of contrast sensitivity measurements of each eye in 4 luminance conditions and under 5 spatial frequencies.

A-1.5, B-3, C-6, D-12, and E-18 cpd: spatial frequencies.

${ }^{* *}$ Statistically significant differences between the baseline examination of T1DM patients without ALA supplementation versus after 3 months.

This study was approved by the Ethics Committee of the Medical University of Gdańsk (NKBBN/250/2013).

2.2. Contrast Sensitivity Test. Contrast sensitivity (CS) was evaluated with the Functional Acuity Contrast Test (FACT, Stereo Optical; USA). This test provides presentation of sinewave gratings of different spatial frequencies $(1.5,3,6,12$, and 18 cycles per degree (cpd)) with a contrast-level change step corresponding to $0.15 \log$ contrast sensitivity (logCS). Following the manufacturer's recommendation, the testing distance was $6 \mathrm{~m}$ for distance. An evaluation of the CS was done monocularly in all groups as a baseline examination and controlled after 3 months. The optimum additional spectacle corrections were used for distance. The CS measurements were performed under 4 chart luminance conditions (LC): $85.0 \mathrm{~cd} / \mathrm{m}^{2}, 3.0 \mathrm{~cd} / \mathrm{m}^{2}, 85 \mathrm{~cd} / \mathrm{m}^{2}$ with illumination $135 \mathrm{lux} / 28 \mathrm{lux}$, and $3.0 \mathrm{~cd} / \mathrm{m}^{2}$ with illumination $135 \mathrm{lux} / 28 \mathrm{lux}$.
CS was analyzed first at the photopic level $\left(85.0 \mathrm{~cd} / \mathrm{m}^{2}\right)$ and then under the mesopic level $\left(3.0 \mathrm{~cd} / \mathrm{m}^{2}\right)$.

2.3. Statistical Analysis. All statistical calculations were performed using a statistical computer programme STATISTICA version 10.0. The data were checked for adherence to normal distribution by using the Shapiro-Wilk test. For the statistical comparison between groups, the Mann-Whitney $U$ test was used. Differences with $P$ value less than 0.05 were considered statistically significant.

\section{Results}

3.1. Subjects' Clinical Characteristics. Clinical characteristics of the studied patients with T1DM and T2DM as well as the control subjects are presented in Table 1 . The study included 
TABLE 3: Characteristics of contrast sensitivity examinations in T2DM patients with and without ALA supplementation at baseline and after 3 months.

\begin{tabular}{|c|c|c|c|c|c|c|}
\hline \multirow[t]{2}{*}{ Spatial frequencies } & \multicolumn{3}{|c|}{$\begin{array}{l}\text { T2DM patients without } \\
\text { ALA supplementation } \\
\mathrm{CS} \times \text { LC }=132 \text { measurements }\end{array}$} & \multicolumn{3}{|c|}{$\begin{array}{c}\text { T2DM patients with } \\
\text { ALA supplementation } \\
\mathrm{CS} \times \mathrm{LC}=200 \text { measurements }\end{array}$} \\
\hline & Baseline & After 3 months & $P$ value & Baseline & After 3 months & $P$ value \\
\hline \multicolumn{7}{|l|}{ A-1.5 cpd } \\
\hline Mean. \pm SD & $5.7 \pm 1.7$ & $5.3 \pm 1.7$ & & $5.8 \pm 1.6$ & $5.7 \pm 1.5$ & \\
\hline Range & $1.0-9.0$ & $0.0-9.0$ & $P=0.000^{* *}$ & $0.0-9.0$ & $1.0-9.0$ & $P=0.451$ \\
\hline Median & 6.0 & 5.0 & & 6.0 & 6.0 & \\
\hline $95 \% \mathrm{CI}$ & {$[5.4 ; 6.0]$} & {$[5.0 ; 5.5]$} & & {$[5.6 ; 6.0]$} & {$[5.5 ; 5.9]$} & \\
\hline \multicolumn{7}{|l|}{ B-3 cpd } \\
\hline Mean. \pm SD & $5.0 \pm 1.8$ & $4.7 \pm 1.9$ & & $5.2 \pm 1.7$ & $5.3 \pm 1.6$ & \\
\hline Range & $0.0-8.0$ & $0.0-9.0$ & $P=0.001^{* *}$ & $0.0-8.0$ & $0.0-9.0$ & $P=0.7371$ \\
\hline Median & 5.0 & 5.0 & & 5.0 & 5.0 & \\
\hline $95 \% \mathrm{CI}$ & {$[4.7 ; 5.4]$} & {$[4.3 ; 5.0]$} & & {$[5.0 ; 5.5]$} & {$[5.0 ; 5.5]$} & \\
\hline \multicolumn{7}{|l|}{ C-6 cpd } \\
\hline Mean. \pm SD & $3.9 \pm 2.3$ & $3.5 \pm 2.2$ & & $4.3 \pm 2.3$ & $4.4 \pm 2.1$ & \\
\hline Range & $0.0-9.0$ & $0.0-8.0$ & $P=0.001^{* *}$ & $0.0-9.0$ & $0.0-9.0$ & $P=0.377$ \\
\hline Median & 4.0 & 4.0 & & 5.0 & 4.5 & \\
\hline $95 \% \mathrm{CI}$ & {$[3.5 ; 4.3]$} & {$[3.1 ; 3.9]$} & & {$[3.9 ; 4.6]$} & {$[4.1 ; 4.7]$} & \\
\hline \multicolumn{7}{|l|}{$\mathrm{D}-12 \mathrm{cpd}$} \\
\hline Mean. \pm SD & $2.1 \pm 2.3$ & $2.1 \pm 2.1$ & & $2.7 \pm 2.2$ & $3.0 \pm 2.2$ & \\
\hline Range & $0.0-7.0$ & $0.0-7.0$ & $P=0.866$ & $0.0-8.0$ & $0.0-9.0$ & $P=0.001^{*}$ \\
\hline Median & 1.0 & 2.0 & & 3.0 & 3.0 & \\
\hline $95 \%$ CI & {$[1.7 ; 2.5]$} & {$[1.7 ; 2.5]$} & & {$[2.3 ; 3.0]$} & {$[2.7 ; 3.3]$} & \\
\hline \multicolumn{7}{|l|}{ E-18 cpd } \\
\hline Mean. \pm SD & $1.2 \pm 1.9$ & $1.1 \pm 1.8$ & & $1.3 \pm 2.0$ & $1.6 \pm 2.0$ & \\
\hline Range & $0.0-7.0$ & $0.0-7.0$ & $P=0.329$ & $0.0-9.0$ & $0.0-8.0$ & $P=0.013^{*}$ \\
\hline Median & 0.0 & 0.0 & & 0.0 & 0.0 & \\
\hline $95 \% \mathrm{CI}$ & {$[0.9 ; 1.5]$} & {$[0.8 ; 1.4]$} & & {$[1.0 ; 1.6]$} & {$[1.3 ; 1.9]$} & \\
\hline
\end{tabular}

CS $\times$ LC: the number of contrast sensitivity measurements of each eye in 4 luminance conditions and under 5 spatial frequencies.

A-1.5, B-3, C-6, D-12, and E-18 cpd: spatial frequencies.

* Statistically significant differences between the baseline examination of T2DM patients with ALA supplementation versus after 3 months

** Statistically significant differences between the baseline examination of T2DM patients without ALA supplementation versus after 3 months.

12 T1DM patients aged $43 \pm 12$ years and the mean duration of the disease was $19 \pm 12$ years. In this study group, there were 12 eyes without DR and 12 eyes with nonproliferative DR. In addition, we also examined 48 patients with type 2 diabetes mellitus aged $59 \pm 10$ years, $7 \pm 8$ years since diagnosis. In this group, there were 71 eyes without DR and 12 eyes with nonproliferative DR and the control group was represented by 20 healthy people aged $33 \pm 8$ years; 38 eyes participated in this prospective study. In the tested group, 5 patients with T1DM were receiving ALA supplementation in the dose of $300 \mathrm{mg}$ once daily for 3 months. 28 patients with T2DM as well as 14 healthy controls were also receiving $300 \mathrm{mg}$ of ALA orally once daily for 3 months (Table 1).

3.2. Effect of Oral Supplementation ALA on CS in Patients with T1DM. In patients with T1DM who in the tested group did not receive ALA supplementation, there was statistically significantly lower contrast sensitivity reported $(6.5 \pm 1.5$ versus $6.0 \pm 1.6, P=0.009 ; 6.0 \pm 1.4$ versus $5.5 \pm 1.6, P=0.010$; $5.3 \pm 2.2$ versus $4.8 \pm 2.0, P=0.005 ; 3.6 \pm 2.6$ versus $3.1 \pm 2.4$, $P=0.020)$ with spatial frequencies A-1.5, B-3, C-6, and D-12 cpd, respectively. However, no statistically significant difference in contrast sensitivity $(5.6 \pm 1.1$ versus $5.6 \pm 1.2$, $P=0.614 ; 5.1 \pm 1.7$ versus $5.0 \pm 1.6, P=0.77 ; 4.2 \pm 2.2$ versus $4.2 \pm 2.2, P=0.947 ; 2.9 \pm 2.3$ versus $2.7 \pm 2.3, P=0.626 ; 1.7 \pm 1.9$ versus $1.5 \pm 1.9, P=0.365)$ at the tested spatial frequencies of A-1.5, B-3, C-6, D-12, and E-16 cpd was seen in T1DM patients who had received ALA supplementation for three months as compared with the baseline (Table 2).

3.3. Effect of Oral Supplementation ALA on CS in Patients with T2DM. In the study group of patients with T2DM, who were not supplemented with ALA at the dose of $300 \mathrm{mg}$ once daily, the reported contrast sensitivity was significantly lower 
TABLE 4: Characteristics of contrast sensitivity examinations in the control group with and without ALA supplementation at baseline and after 3 months.

\begin{tabular}{|c|c|c|c|c|c|c|}
\hline \multirow[t]{2}{*}{ Spatial frequencies } & \multicolumn{3}{|c|}{$\begin{array}{l}\text { Control group without } \\
\text { ALA supplementation } \\
\mathrm{CS} \times \mathrm{LC}=44 \text { measurements }\end{array}$} & \multicolumn{3}{|c|}{$\begin{array}{c}\text { Control group with } \\
\text { ALA supplementation } \\
\mathrm{CS} \times \mathrm{LC}=108 \text { measurements }\end{array}$} \\
\hline & Baseline & $\begin{array}{l}\text { After } 3 \\
\text { months }\end{array}$ & $P$ value & Baseline & $\begin{array}{l}\text { After } 3 \\
\text { months }\end{array}$ & $P$ value \\
\hline \multicolumn{7}{|l|}{ A-1.5 cpd } \\
\hline Mean. \pm SD & $6.9 \pm 1.6$ & $6.7 \pm 1.3$ & & $6.7 \pm 1.6$ & $6.8 \pm 1.2$ & \\
\hline Range & $4.0-9.0$ & $5.0-9.0$ & $P=0.318$ & $0.0-9.0$ & $5.0-9.0$ & $P=0.465$ \\
\hline Median & 7.0 & 7.0 & & 7.0 & 7.0 & \\
\hline $95 \%$ CI & {$[6.4 ; 7.4]$} & {$[6.3 ; 7.1]$} & & {$[6.4 ; 7.0]$} & {$[6.6 ; 7.1]$} & \\
\hline \multicolumn{7}{|l|}{ B-3 cpd } \\
\hline Mean. \pm SD & $6.8 \pm 1.6$ & $6.7 \pm 1.6$ & & $6.1 \pm 1.5$ & $6.4 \pm 1.2$ & \\
\hline Range & $3.0-9.0$ & $3.0-9.0$ & $P=0.423$ & $0.0-9.0$ & $3.0-9.0$ & $P=0.027^{*}$ \\
\hline Median & 6.5 & 7.0 & & 6.0 & 7.0 & \\
\hline $95 \% \mathrm{CI}$ & {$[6.3 ; 7.3]$} & {$[6.2 ; 7.2]$} & & {$[5.8 ; 6.4]$} & {$[6.2 ; 6.7]$} & \\
\hline \multicolumn{7}{|l|}{ C-6 cpd } \\
\hline Mean. \pm SD & $5.9 \pm 1.8$ & $6.0 \pm 1.5$ & & $5.4 \pm 1.9$ & $5.5 \pm 1.7$ & \\
\hline Range & $1.0-9.0$ & $2.0-8.0$ & $P=0.414$ & $0.0-8.0$ & $0.0-8.0$ & $P=0.399$ \\
\hline Median & 6.0 & 6.0 & & 5.0 & 6.0 & \\
\hline $95 \% \mathrm{CI}$ & {$[5.3 ; 6.4]$} & {$[5.5 ; 6.4]$} & & {$[5.1 ; 5.8]$} & {$[5.2 ; 5.8]$} & \\
\hline \multicolumn{7}{|l|}{$\mathrm{D}-12 \mathrm{cpd}$} \\
\hline Mean. \pm SD & $4.4 \pm 2.3$ & $4.5 \pm 2.2$ & & $4.3 \pm 1.9$ & $4.2 \pm 1.9$ & \\
\hline Range & $0.0-9.0$ & $0.0-9.0$ & $P=0.648$ & $0.0-8.0$ & $0.0-8.0$ & $P=0.446$ \\
\hline Median & 4.0 & 4.5 & & 4.0 & 4.0 & \\
\hline $95 \%$ CI & {$[3.7 ; 5.1]$} & {$[3.8 ; 5.2]$} & & {$[3.9 ; 4.7]$} & {$[3.8 ; 4.5]$} & \\
\hline \multicolumn{7}{|l|}{ E-18 cpd } \\
\hline Mean. \pm SD & $2.9 \pm 2.6$ & $2.5 \pm 2.4$ & & $2.9 \pm 2.2$ & $2.6 \pm 1.9$ & \\
\hline Range & $0.0-9.0$ & $0.0-8.0$ & $P=0.127$ & $0.0-9.0$ & $0.0-7.0$ & $P=0.234$ \\
\hline Median & 3.0 & 2.0 & & 3.0 & 2.0 & \\
\hline $95 \% \mathrm{CI}$ & {$[2.1 ; 3.7]$} & {$[1.8 ; 3.3]$} & & {$[2.5 ; 3.3]$} & {$[2.3 ; 3.0]$} & \\
\hline
\end{tabular}

CS $\times$ LC: the number of contrast sensitivity measurements of each eye in 4 luminance conditions and under 5 spatial frequencies. Spatial frequencies: A-1.5, B-3, C-6, D-12, and E-18 cpd.

${ }^{*}$ Statistically significant differences between the baseline examination of control group with ALA supplementation versus after 3 months.

$(5.7 \pm 1.7$ versus $5.3 \pm 1.7, P=0.000 ; 5.0 \pm 1.8$ versus $4.7 \pm 1.9$ $P=0.001 ; 3.9 \pm 2.3$ versus $3.5 \pm 2.2, P=0.001)$ at the spatial frequency of A-1.5, B-3, and C-6 cpd, respectively. However, no statistically significant difference in contrast sensitivity was shown $(2.1 \pm 2.3$ versus $2.1 \pm 2.1, P=0.866$, and $1.2 \pm 1.9$ versus $1.1 \pm 1.8, P=0.329)$ at the tested spatial frequencies of D-12 and E-16 cpd, respectively, in T2DM patients who had not received ALA supplementation in the dose of $300 \mathrm{mg}$ once daily for three months, as compared with the baseline. On the other hand, in T2DM patients who had received ALA supplementation in the dose of $300 \mathrm{mg}$ once daily for three months, contrast sensitivity had improved significantly $(2.7 \pm 2.2$ versus $3.0 \pm 2.2, P=0.001$, and $1.3 \pm 2.0$ versus $1.6 \pm 2.0, P=0.013$ ), respectively, at the spatial frequencies of D-12 and E-16 cpd. While examining T2DM patients who had received ALA supplementation for three months, we have not though observed any statistically significant difference in contrast sensitivity $(5.8 \pm 1.6$ versus $5.7 \pm 1.5, P=0.451$, $5.2 \pm 1.7$ versus $5.3 \pm 1.6, P=0.737$, and $4.3 \pm 2.3$ versus $4.4 \pm 2.1, P=0.377$ ) respectively, at the frequencies of $\mathrm{A}-1.5$, B-3, and C-6 cpd, as compared with the baseline (Table 3).

3.4. Effect of Oral Supplementation ALA on CS in Healthy Control Subjects. In the control group of healthy volunteers who had received ALA supplementation in the dose of $300 \mathrm{mg}$ once daily for three months, a statistically significant contrast sensitivity improvement had been observed only at the spatial frequency B-3 $(6.1 \pm 1.5$ versus $6.4 \pm 1.2, P=$ 0.027 ) as compared with the baseline. However, in the healthy control group, no statistical significance had been obtained at other tested frequencies after three months as compared with the baseline, regardless of whether the participants had received ALA supplementation in the dose of $300 \mathrm{mg}$ once daily (Table 4). 


\section{Discussion}

So far, there has been little research that would evaluate the effects of oral treatment of patients with ALA for the help on CS in patients with T1DM and T2DM. Therefore, the aim of this study was to estimate the effect of oral supplementation with ALA on CS in patients with T1DM and T2DM. In the group of patients with T1DM receiving ALA for 3 months CS remained stable. However, in the group of patients with T1DM without ALA supplementation, significant deterioration of CS at spatial frequencies A-1.5, B-3, C-6, and D-12 cpd was observed. On the other hand, in T2DM patients on ALA supplementation CS improved after 3 months at spatial frequencies D-12 and E-18 cpd, whereas the group of T2DM patients not receiving ALA had a significant CS reduction at spatial frequencies A-1.5, B-3 and C-6 cpd. Previous sparse studies have shown that ALA and DHLA play a very important role in the treatment of microvascular dysfunction in patients with diabetes [17-19]. Du et al. showed that oral treatment with ALA combined with benfotiamine (synthetic vitamin B1) normalized increased AGE formation and reduced hexosamine pathway activity and prostacyclin synthesis in patients with type 1 DM [19]. In addition, Lin et al. examined the effect of ALA (Renantiomer) at $60 \mathrm{mg} / \mathrm{kg}$ dose i.p. (5 days per week for 30 weeks) on diabetic rats with experimental DR [20]. Authors showed that after this treatment the number of acellular capillaries was significantly reduced and pericyte loss was inhibited. Moreover, they presented the evidence that ALA reduces oxidative stress, normalizes increased NF kappa $B$, AGE, and RAGE, and reduces VEGF upregulation by $43 \%$ [20]. According to Kowluru and Odenbach, long-term oral administration of ALA ( $400 \mathrm{mg} / \mathrm{kg}$ for 11 months) in diabetic rats inhibits capillary cell apoptosis and also reduces the number of acellular capillaries in the retina [30].

Currently, ophthalmologists have a great diagnostic tool for detection of vision impairment through contrast sensitivity test, a more sensitive instrument than standard visual acuity measures $[14,15]$. In our control group, CS remained stable among the patients without ALA supplementation, while a significant CS improvement after 3-month ALA supplementation at spatial frequency $3 \mathrm{cpd}$ was noticed. During our 3-month study, all studied subjects had stable visual acuity and eye fundus image; however, changes in the CS were observed. Moreover, CS improvement after ALA supplementation appeared only in the T2DM group, whether it had no influence on CS among the T1DM patients. We suggest that ALA supplementation has improved insulin sensitivity in patients with T2DM. Other clinical studies, carried out in patients with type $2 \mathrm{DM}$, provided evidence that both intravenous and oral treatment with ALA improve insulinstimulated glucose disposal [31, 32]. Moreover, Bucolo et al. demonstrated that the fortified extract of red berries, Ginkgo biloba, and white willow bark containing L-carnosine and ALA may blunt some of the negative effects due to hyperglycemia, such as inflammation, oxidation, and VEGF expression in early retinal and plasma changes of diabetic rats [21].
Our research has shown that oral 3-month supplementation with ALA at a relatively low $300 \mathrm{mg}$ and convenient once daily dose maintains functional vision in T1DM patients and improves it in T2DM patients. Concurrently, reduction of CS in both patients with T1DM and T2DM without ALA supplementation was observed. In the control group on ALA supplementation, CS improvement was noticed at one spatial frequency.

In summary, our results suggest that supplementation with ALA represents an achievable adjunct therapy to help prevent loss of vision in diabetic patients. Further investigations are needed to evaluate the influence of oral supplementation of ALA in patients with T1DM and T2DM.

\section{Conflict of Interests}

The authors declare that there is no conflict of interests regarding the publication of this paper.

\section{References}

[1] K. Haskins, B. Bradley, K. Powers et al., "Oxidative stress in type 1 diabetes," Annals of the New York Academy of Sciences, vol. 1005 , pp. 43-54, 2003.

[2] A. P. Adamis, "Is diabetic retinopathy an inflammatory disease?" British Journal of Ophthalmology, vol. 86, no. 4, pp. 363$365,2002$.

[3] H. Shamoon, H. Duffy, N. Fleischer et al., "The effect of intensive treatment of diabetes on the development and progression of long-term complications in insulin-dependent diabetes mellitus," The New England Journal of Medicine, vol. 329, no. 14, pp. 977-986, 1993.

[4] R. Turner, "Intensive blood-glucose control with sulphonylureas or insulin compared with conventional treatment and risk of complications in patients with type 2 diabetes (UKPDS 33)," The Lancet, vol. 352, no. 9131, pp. 837-853, 1998.

[5] M. Brownlee, "Biochemistry and molecular cell biology of diabetic complications," Nature, vol. 414, no. 6865, pp. 813-820, 2001.

[6] X. Du, T. Matsumura, D. Edelstein et al., "Inhibition of GAPDH activity by poly(ADP-ribose) polymerase activates three major pathways of hyperglycemic damage in endothelial cells," The Journal of Clinical Investigation, vol. 112, no. 7, pp. 1049-1057, 2003.

[7] M. Brownlee, "The pathobiology of diabetic complications: a unifying mechanism," Diabetes, vol. 54, no. 6, pp. 1615-1625, 2005.

[8] H. Zong, M. Ward, and A. W. Stitt, "AGEs, RAGE, and diabetic retinopathy," Current Diabetes Reports, vol. 11, no. 4, pp. 244252, 2011.

[9] K. Kaul, A. Hodgkinson, J. M. Tarr, E. M. Kohner, and R. Chibber, "Is inflammation a common retinal-renal-nerve pathogenic link in diabetes?" Current Diabetes Reviews, vol. 6, no. 5, pp. 294-303, 2010.

[10] S. Kaštelan, M. Tomić, A. Gverović Antunica, J. S. Rabatić, and S. Ljubić, "Inflammation and pharmacological treatment in diabetic retinopathy," Mediators of Inflammation, vol. 2013, Article ID 213130, 8 pages, 2013.

[11] Y. Du, A. Veenstra, K. Palczewski, and T. S. Kern, "Photoreceptor cells are major contributors to diabetes-induced oxidative 
stress and local inflammation in the retina," Proceedings of the National Academy of Sciences of the United States of America, vol. 110, no. 41, pp. 16586-16591, 2013.

[12] X.-L. Zhang, L. Wen, Y.-J. Chen, and Y. Zhu, "Vascular endothelial growth factor up-regulates the expression of intracellular adhesion molecule-1 in retinal endothelial cells via reactive oxygen species, but not nitric oxide," Chinese Medical Journal, vol. 122, no. 3, pp. 338-343, 2009.

[13] C. D. Georgakopoulos, M. I. Eliopoulou, A. M. Exarchou, V. Tzimis, N. M. Pharmakakis, and B. E. Spiliotis, "Decreased contrast sensitivity in children and adolescents with type 1 diabetes mellitus," Journal of Pediatric Ophthalmology and Strabismus, vol. 48, no. 2, pp. 92-97, 2011.

[14] J. Krasny, M. Andel, R. Brunnerova et al., "The contrast sensitivity test in early detection of ocular changes in the relation to the type I diabetes mellitus compensation in children, teenagers, and young adults," Recent Patents on Inflammation \& Allergy Drug Discovery, vol. 1, no. 3, pp. 232-236, 2007.

[15] A. Y. Sukha and A. Rubin, "High, medium, and low contrast visual acuities in diabetic retinal disease," Optometry \& Vision Science, vol. 86, no. 9, pp. 1086-1095, 2009.

[16] M. Gualtieri, M. Bandeira, R. D. Hamer, F. M. Damico, A. L. A. Moura, and D. F. Ventura, "Contrast sensitivity mediated by inferred magno- and parvocellular pathways in type 2 diabetics with and without nonproliferative retinopathy," Investigative Ophthalmology \& Visual Science, vol. 52, no. 2, pp. 1151-1155, 2011.

[17] S. K. Hegazy, O. A. Tolba, T. M. Mostafa, M. A. Eid, and D. R. ElAfify, "Alpha-lipoic acid improves subclinical left ventricular dysfunction in asymptomatic patients with type 1 diabetes," The Review of Diabetic Studies, vol. 10, no. 1, pp. 58-67, 2013.

[18] A. Udupa, P. Nahar, S. Shah, M. Kshirsagar, and B. Ghongane, "A comparative study of effects of omega-3 fatty acids, alpha lipoic Acid and vitamin e in type 2 diabetes mellitus," Annals of Medical and Health Sciences Research, vol. 3, no. 3, pp. 442-446, 2013.

[19] X. Du, D. Edelstein, and M. Brownlee, "Oral benfotiamine plus $\alpha$-lipoic acid normalises complication-causing pathways in type 1 diabetes," Diabetologia, vol. 51, no. 10, pp. 1930-1932, 2008.

[20] J. Lin, A. Bierhaus, P. Bugert et al., "Effect of R-(+)- $\alpha$-lipoic acid on experimental diabetic retinopathy," Diabetologia, vol. 49, no. 5, pp. 1089-1096, 2006.

[21] C. Bucolo, G. Marrazzo, C. B. M. Platania, F. Drago, G. M. Leggio, and S. Salomone, "Fortified extract of red berry, gingko biloba, and white willow bark in experimental early diabetic retinopathy," Journal of Diabetes Research, vol. 2013, Article ID 432695, 6 pages, 2013.

[22] L. J. Reed, "A trail of research from lipoic acid to $\alpha$-keto acid dehydrogenase complexes," The Journal of Biological Chemistry, vol. 276, no. 42, pp. 38329-38336, 2001.

[23] J.-P. Carreau, "Biosynthesis of lipoic acid via unsaturated fatty acids," Methods in Enzymology, vol. 62, pp. 152-158, 1979.

[24] G. P. Biewenga, G. R. M. M. Haenen, and A. Bast, "The pharmacology of the antioxidant: lipoic acid," General Pharmacology, vol. 29, no. 3, pp. 315-331, 1997.

[25] P. J. Randle, "Regulatory interactions between lipids and carbohydrates: the glucose fatty acid cycle after 35 years," Diabetes/Metabolism Reviews, vol. 14, no. 4, pp. 263-283, 1998.

[26] L. Packer, E. H. Witt, and H. J. Tritschler, "Alpha-lipoic acid as a biological antioxidant," Free Radical Biology \& Medicine, vol. 19, no. 2, pp. 227-250, 1995.
[27] W. Jones, X. Li, Z.-C. Qu, L. Perriott, R. R. Whitesell, and J. M. May, "Uptake, recycling, and antioxidant actions of $\alpha$-lipoic acid in endothelial cells," Free Radical Biology \& Medicine, vol. 33, no. 1, pp. 83-93, 2002.

[28] Position of the Polish Diabetes Association, "Clinical recommendations for treatment of patients with diabetes," Journal of the Diabetes Poland, vol. 12, supplement A, pp. 3-7, 2011.

[29] American Diabetes Association, "Diagnosis and classification of diabetes," Diabetes Care, vol. 33, supplement 1, pp. S62-S69, 2010.

[30] R. A. Kowluru and S. Odenbach, "Effect of long-term administration of $\alpha$-lipoic acid on retinal capillary cell death and the development of retinopathy in diabetic rats," Diabetes, vol. 53, no. 12, pp. 3233-3238, 2004.

[31] S. Porasuphatana, S. Suddee, A. Nartnampong, J. Konsil, B. Harnwong, and A. Santaweesuk, "Glycemic and oxidative status of patients with type 2 diabetes mellitus following oral administration of alpha-lipoic acid: a randomized double-blinded placebo-controlled study," Asia Pacific Journal of Clinical Nutrition, vol. 21, no. 1, pp. 12-21, 2012.

[32] A. S. Udupa, P. S. Nahar, S. H. Shah, M. J. Kshirsagar, and B. B. Ghongane, "Study of comparative effects of antioxidants on insulin sensitivity in type 2 diabetes mellitus," Journal of Clinical and Diagnostic Research, vol. 6, no. 9, pp. 1469-1473, 2012. 


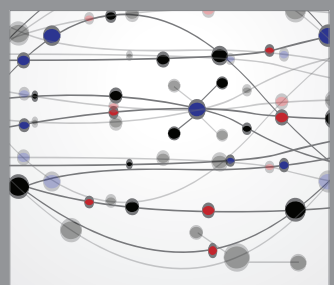

The Scientific World Journal
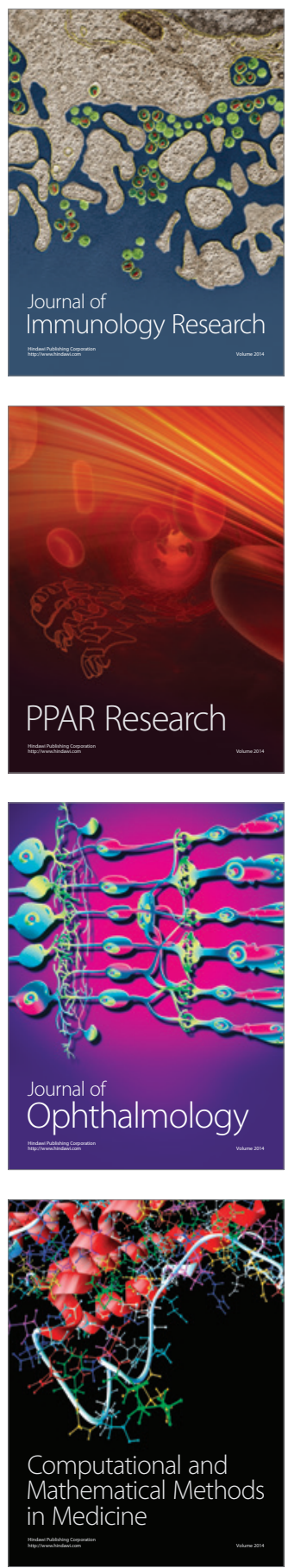

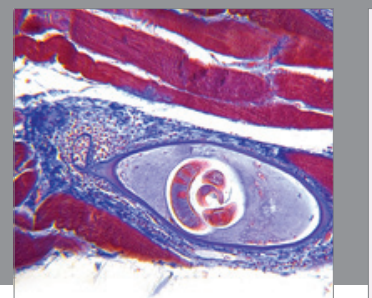

Gastroenterology

Research and Practice
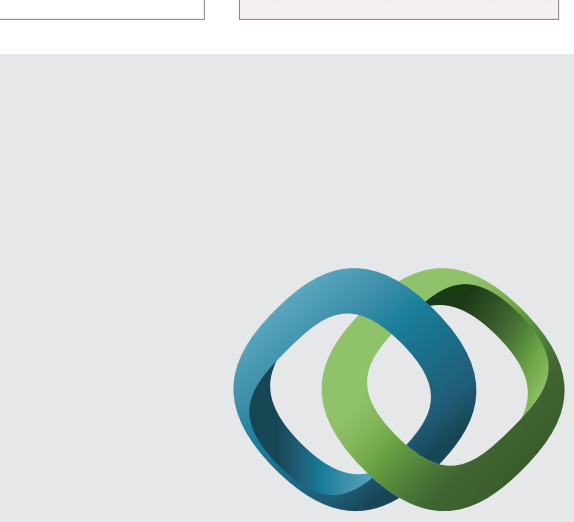

\section{Hindawi}

Submit your manuscripts at

http://www.hindawi.com
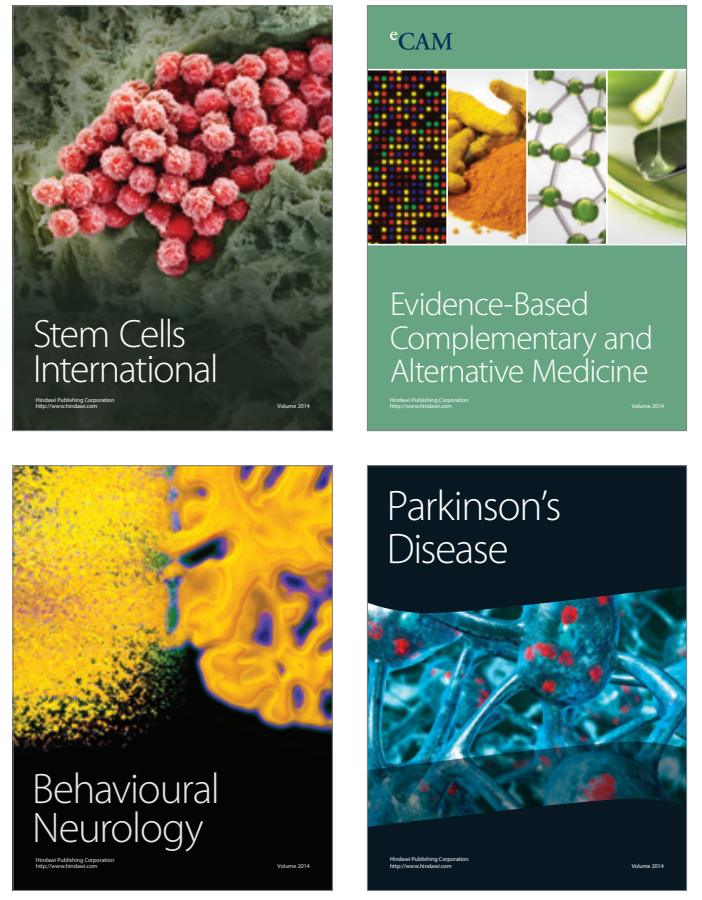
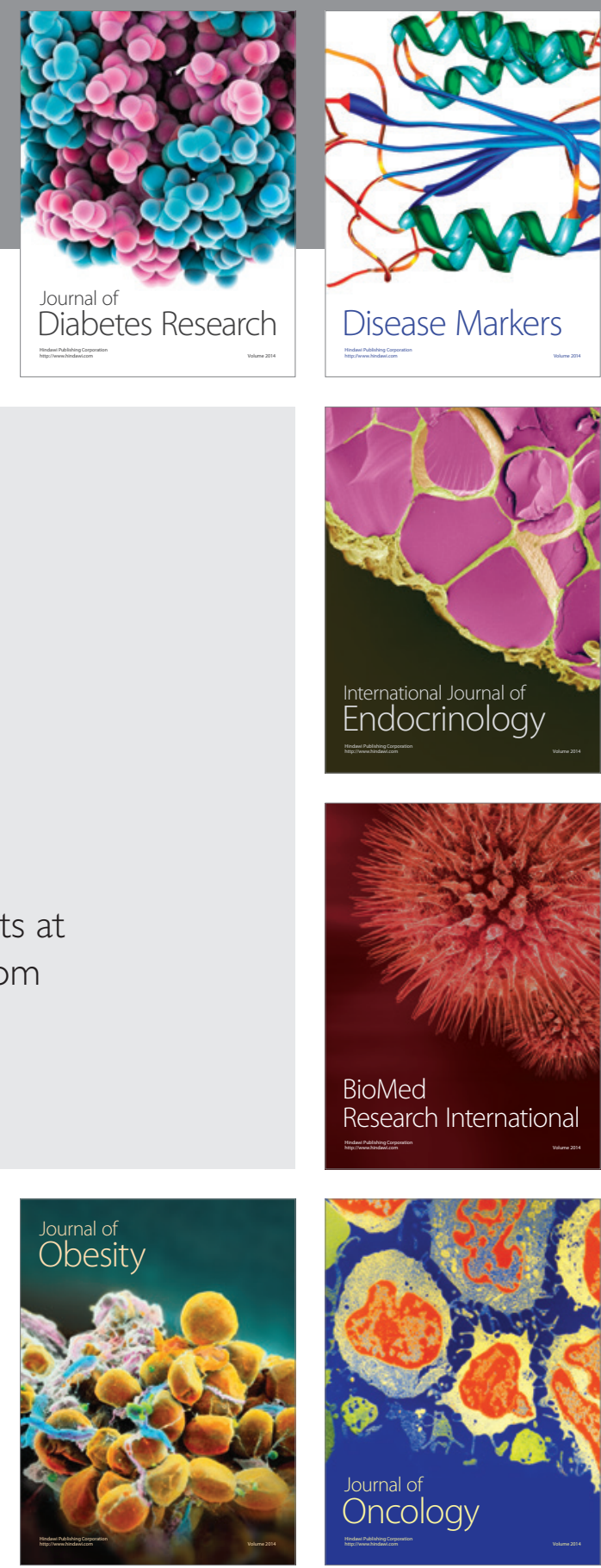

Disease Markers
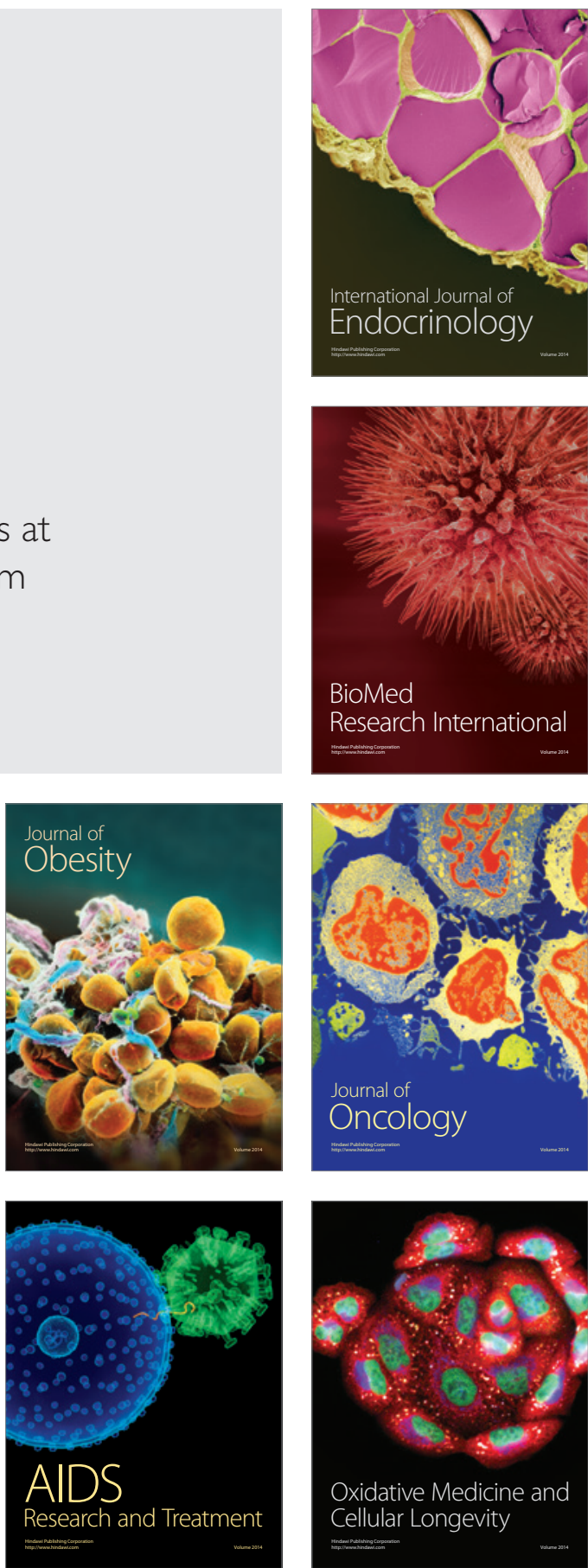